\title{
Nocturnal incontinence in children with fetal alcohol spectrum disorders (FASD) in a South African cohort
}

Citation for published version (APA):

Roozen, S., Olivier, L., Niemczyk, J., von Gontard, A., Peters, G-J. Y., Kok, G., Viljoen, D., \& Curfs, L. (2017). Nocturnal incontinence in children with fetal alcohol spectrum disorders (FASD) in a South African cohort. Journal of Pediatric Urology, 13(5), 496.e1-496.e7. https://doi.org/10.1016/j.jpurol.2017.02.009

Document status and date:

Published: 01/10/2017

DOI:

10.1016/j.jpurol.2017.02.009

Document Version:

Publisher's PDF, also known as Version of record

Document license:

Taverne

Please check the document version of this publication:

- A submitted manuscript is the version of the article upon submission and before peer-review. There can be important differences between the submitted version and the official published version of record.

People interested in the research are advised to contact the author for the final version of the publication, or visit the DOI to the publisher's website.

- The final author version and the galley proof are versions of the publication after peer review.

- The final published version features the final layout of the paper including the volume, issue and page numbers.

Link to publication

\footnotetext{
General rights rights.

- You may freely distribute the URL identifying the publication in the public portal. please follow below link for the End User Agreement:

www.umlib.nl/taverne-license

Take down policy

If you believe that this document breaches copyright please contact us at:

repository@maastrichtuniversity.nl

providing details and we will investigate your claim.
}

Copyright and moral rights for the publications made accessible in the public portal are retained by the authors and/or other copyright owners and it is a condition of accessing publications that users recognise and abide by the legal requirements associated with these

- Users may download and print one copy of any publication from the public portal for the purpose of private study or research.

- You may not further distribute the material or use it for any profit-making activity or commercial gain

If the publication is distributed under the terms of Article $25 \mathrm{fa}$ of the Dutch Copyright Act, indicated by the "Taverne" license above, 


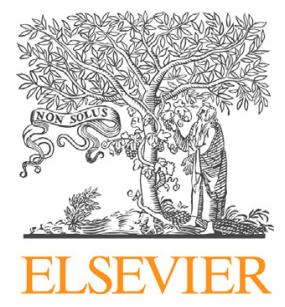

${ }^{\mathrm{a} G o v e r n o r ~ K r e m e r s ~ C e n t r e ~-~}$ Maastricht University Medical Centre+, Maastricht, The Netherlands

bDepartment of Work and Social Psychology, Maastricht University, Maastricht, The Netherlands

'Foundation for Alcohol Related Research, Bellville, South Africa

${ }^{\mathrm{d} D i v i s i o n}$ of Molecular Biology and Human Genetics, Faculty of Health Sciences, Stellenbosch University and Tygerberg Hospital, Cape Town, South Africa

eDepartment of Child and Adolescent Psychiatry, Saarland University Hospital, Homburg, Germany

${ }^{f}$ Faculty of Psychology and Education Science, Open University of the Netherlands, Heerlen, The Netherlands

'Department of Human Genetics, University of the Witwatersrand, Johannesburg, South Africa

Correspondence to: S. Roozen, Governor Kremers Centre Maastricht University Medical Centre+, PO Box 5800, 6202 AZ Maastricht, The Netherlands

sylvia.roozen@maas-

trichtuniversity.nl (S. Roozen)

\section{Keywords}

Fetal alcohol syndrome; Fetal alcohol spectrum disorder(s); Daytime urinary incontinence; Nocturnal enuresis; Fecal incontinence

Received 21 September 2016 Accepted 12 February 2017 Available online 23 March 2017

\section{Nocturnal incontinence in children with fetal alcohol spectrum disorders (FASD) in a South African cohort}

\author{
Sylvia Roozen ${ }^{\mathrm{a}, \mathrm{b}}$, Leana Olivier ${ }^{\mathrm{a}, \mathrm{c}, \mathrm{d}}$, Justine Niemczyk ${ }^{\mathrm{a}, \mathrm{e}}$, \\ Alexander von Gontard $^{\text {a,e }}$, Gjalt-Jorn Y. Peters ${ }^{\text {b,f }}$, Gerjo Kok ${ }^{\mathrm{a}, \mathrm{b}}$, \\ Denis Viljoen ${ }^{\mathrm{c}, \mathrm{d}, \mathrm{g}}$, Leopold Curfs ${ }^{\mathrm{a}}$
}

Summary

Introduction

Fetal alcohol spectrum disorders (FASD) are one of the leading preventable causes of intellectual disabilities (ID). Not much is known about the topic of pediatric incontinence related to FASD, for example nocturnal enuresis (NE), daytime urinary incontinence (DUI), and fecal incontinence (FI). So far, incontinence problems have been examined among children with other specific syndromes.

\section{Objective}

The aim of the present study is to investigate the possible presence of incontinence among children with FASD in a South African cohort.

\section{Study design}

The South African version of the combined questionnaire including the "Parental Questionnaire: Enuresis/Urinary Incontinence" and "Encopresis Questionnaire - Screening Version"; and lower urinary tract symptoms (LUTS) were assessed by the "International-Consultation-on-Incontinence-Questionnaire - Pediatric Lower Urinary Tract Symptom" (ICIQ-CLUTS) among 99 interviewees (e.g. mothers, grandparents) of children with FASD. Moreover, scores on the "Griffiths Mental Development Scales Extended Revised" (GMDS-ER) were obtained of all included children for further statistical analysis.
Results

The overall incontinence rate was 20\% $(n=20)$, in children diagnosed within the FASD spectrum (fetal alcohol syndrome or FAS $n=17$, partial fetal alcohol syndrome or pFAS, $n=1$, alcohol related neurodevelopmental disorder or ARND $n=2$ ). NE affected $16 \%(n=16)$ of children with a FASD (FAS $n=13$, pFAS $n=1$, and ARND $n=2$ ). DUI was reported in one child (FAS), and $\mathrm{FI}$ in $4 \%(n=4)$ of children (again, only FAS). No indication of lower urinary tract symptoms (LUTS) in the clinical range was reported (sample mean score $=5.17$ ). Based on the GMDS-ER, $88 \%$ of the children scored lower than 10 th percentile.

\section{Discussion}

This is a first study to examine the problems of incontinence among children diagnosed within the spectrum of FASD. The rates for children with a FASD are lower than the rates for many children with special needs, but much higher than for typically developing children. Children with a FASD are mainly affected by NE.

\section{Conclusion}

The problem of incontinence among children with a FASD in South Africa needs to be assessed and considered for clinical management. Future research is necessary to examine problems of incontinence in relation to cognitive and behavioral functioning among children with a FASD, as well as identifying possible causes. 


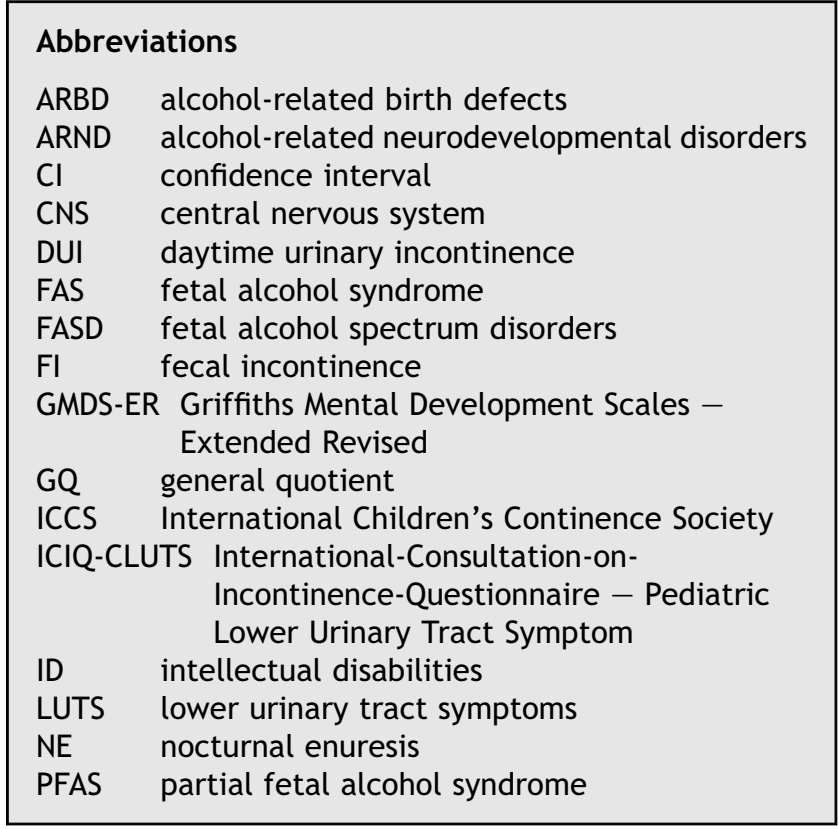

\section{Introduction}

Fetal alcohol spectrum disorders (FASD) are the most common preventable causes of developmental disabilities. FASD is an all-compassing term for disorders caused by prenatal alcohol consumption including the diagnosis of fetal alcohol syndrome (FAS), partial fetal alcohol syndrome (pFAS), alcohol related neurodevelopmental disorder (ARND), and alcohol related birth defects (ARBD). Potential consequences of FASD are abnormalities in the central nervous system (CNS). These may include structural (e.g. small head circumference), neurological, or functional deficits (e.g. poor executive functioning, motor functioning delays, poor social skills, poor decision making, or memory deficits) [1,2]. Global prevalence estimates range from 0 to 176.77 per 1000 livebirths [3]. To date, there are no data available on incontinence in children and adolescents, although this has been described as a problem area for children diagnosed within the spectrum of FASD $[4,5]$.

According to the International Children's Continence Society (ICCS), non-organic urinary incontinence is defined by an intermittent loss of urine in a child aged 5 years or older with a frequency of at least once a month - after organic causes have been ruled out [6]. If it occurs during sleep it is called nocturnal enuresis (or just enuresis) (NE), and if it manifests during the daytime, daytime urinary incontinence (DUI). Many different subtypes can be differentiated. Fecal incontinence $(\mathrm{FI})$ is defined by the passage of stool in inappropriate places in a similar way, but is considered to be a condition from the age of 4 years onwards [7,8]. Approximately $10 \%$ of typically developing children aged 7 years have NE, 2-3\% DUI, and $1-3 \% \mathrm{FI}[9,10]$. The rates of all types of incontinence are much higher in children with special needs [11]. In individuals with intellectual disability (ID), the rates of incontinence are inversely related to intelligence, that is the more severe the ID, the higher the likelihood of being affected by incontinence [12]. However, there are differences in rates and types of incontinence from one syndrome to another [11].

Children who suffer from incontinence may develop adverse psychological and social consequences which have an impact on quality of life [13]. Incontinence in children with special needs is not just distressing for the children themselves, but also a burden for parents and caregivers.

Because children diagnosed within the spectrum of FASD may present with a broad array of behavioral and neurodevelopmental impairments, it is suggested that problems of incontinence are also present among children with a FASD. As no study results are available on incontinence among children with a FASD, the aim of the present study is to assess incontinence among a cohort of South African children diagnosed with a FASD.

\section{Materials and methods}

\section{Ethics}

The research project received approval from the Maastricht University ethics committee with reference number ECP. 04-09-2012.

\section{Materials}

Incontinence was assessed by a combined questionnaire including the "Parental Questionnaire: Enuresis/Urinary Incontinence" [14] and "Encopresis Questionnaire Screening Version" [15]. Lower urinary tract symptoms (LUTS) were assessed by the "International-Consultationon-Incontinence-Questionnaire - Pediatric Lower Urinary Tract Symptom" (ICIQ-CLUTS) [16]. The ICIQ-CLUTS is validated in three languages (English, Italian, and German; [16]) but not yet in a South African language. The 10 questions of the ICIQ-CLUTS build a LUTS score with clinically relevant scores over 13 . According to the ICCS, NE and DUI were diagnosed in persons older than 5 years when wetting occurs at least once per month. According to DSM5 , FI was diagnosed from the age of 4 years when soiling occurs at least once per month. Overall incontinence was considered to be present if any subtype of incontinence is present. Moreover, less commonly reported problems of incontinence were described.

To use this questionnaire in this community, it was translated to the appropriate South African language in this community, followed by a back-translation. Small culture relevant adjustments have been made in wording (e.g. "diaper" was replaced by "underwear" as no diapers are being used in this community). Moreover, scores based on the "Griffiths Mental Development Scales - Extended Revised" (GMDS-ER) were included for all subjects [17]. The GMDS-ER measures the mental development of children aged between 2 and 8 years based on six subscales including locomotor (subscale A), personal-social (subscale B), language (subscale C), eye and hand coordination (subscale D), performance (subscale E), and practical reasoning (subscale F). Raw scores were computed for each individual subscale and were converted to a standard score (using zscores and General Quotient) representing a developmental score of the children. 


\section{Study area and population}

The study was conducted in a peri-urban area in the Eastern Cape Province, South Africa and followed a FASD prevalence study [18]. This area has a total population of 182,012 inhabitants from the following cultural groups: $64.4 \%$ mixed ancestry, $34.1 \%$ black, $0.2 \%$ white, $0.6 \%$ Asian/Indian, and other $0.8 \%$. The residence in this area faces many challenges such as poverty, high level of unemployment, recurrent political unrest, and limited health services [19]. The FASD prevalence study was aimed at first-grade children in this area. Out of 1928 consenting children (from 2455), 244 received a FAS, pFAS, ARND, or ARBD diagnosis. Resource limitations (e.g. accessibility) meant it was not possible to include all these children. Hence, a total sample of 99 parents or guardians of these 244 diagnosed firstgraders was randomly selected.

\section{Methods}

Two trained community workers visited all 99 consenting parents or guardians at home to complete the parental questionnaire on incontinence and the structured interviews, thereby overcoming challenges in terms of illiteracy, motivation, and completion of the questionnaires.

\section{Statistical analysis}

Study data were collected and managed using REDCap electronic data capture hosted at the Foundation for Alcohol Related Research (FARR) [20]. The research coordinator verified the captured data by the project manager for a randomly selected sample of questionnaires. Thereafter, data from the parental questionnaires were further processed by the SPSS software package version 22.0 (IBM Corp, IBM SPSS Statistics for Windows, 2013) and R version 3.2.3 ( $R$ Development Core Team. R: A Language and Environment for Statistical Computing, 2016). LUTS scores were calculated whereby a score above 13 was regarded as clinically relevant. Additional data for sample characteristics (e.g. maternal educational attainment, child BMI) and z-scores based on the GMDS-ER were obtained for further analysis. Statistical analyses were then carried out using SPSS software package version 22.0 and $R$ version 3.2.3 using descriptive statistics. For each outcome, primarily 95\% confidence intervals (Cls) were reported, followed by sample point estimates. To keep the probability of making a Type-1 error at 5\%, all $p$-values were adjusted for multiple testing using the False Discovery Rate approach [21]. All statistical analyses are made publicly available (https:// osf.io/g683k/).

\section{Results}

\section{Sample characteristics}

The total sample included 99 children. Sample characteristics are described in Table 1. There was no refusal of participation. The interviewees included mothers $(n=68)$, fathers $(n=5)$, foster parent or guardians $(n=13)$, or other family members (e.g. grandmother, aunt; $n=13$ ). Maternal data showed that the majority of mothers finished high school $(n=84)$, followed by primary school $(n=14)$, and university $(n=1)$. All mothers $(n=99)$ reported alcohol consumption during pregnancy (necessary condition for FASD diagnosis), to be from mixed ancestry, and $80 \%$ reported unwanted pregnancies. The mean approximate age at delivery was 27.14 years (SD 6.89).

All children were previously diagnosed within the FASD spectrum; 72 with FAS, 15 pFAS, 11 ARND, and one ARBD. Age ranged from 6 to 10 years (mean age 8.5 years). The majority of subjects were boys $(n=57)$, and of all children, $11.1 \%$ were prematurely born ( $<37$ weeks). Birth weights ranged from $1200 \mathrm{~g}$ to $3660 \mathrm{~g}$ (mean weight $2608 \mathrm{~g}$, SD 0.536). The body mass index (BMI) ranged from 10.34 to 18.05 (mean BMI 14.27, SD 1.27) and the mean occipital frontal circumference (OFC) was $49.9 \mathrm{~cm}$ (SD 1.58). Current data showed an average weight of $17.78 \mathrm{~kg}$ (SD 2.53) and average height of $111.44 \mathrm{~cm}$ (SD 6.5).

For the population under study there are no reliable biometric reference charts (e.g. OFC, BMI). Compared with other international norms, the majority of children score below the third percentile. Very rare cases score above the 50 th percentile (e.g. charts used in the United States). For example, according to the United States head circumference growth reference charts, the reference values for children aged 6-10 years are 49.2-50.7 (third percentile) for males and 48.75 to 50.10 (third percentile) for females [22]. Compared with the values in the present study, the mean average for males was 49.94 (SD 1.67) and for females 49.9 (SD 1.45).

Data on the GMDS-ER subscales showed that $87.8 \%(n=98)$ had GQ scores below the 10th percentile and $71.7 \%(n=99)$ were severely delayed (z-scores of -2 and lower). Overall zscore averages were 0.34 (SD 5.29) for locomotor, -0.95 (SD 1.19) for personal-social, -2.84 (SD 0.48) for language, -2.11 (SD 0.93) for eye-hand coordination, -0.64 (SD 1.45) for performance, and -2.63 (SD 1.1) for practical reasoning.

Furthermore, $61.6 \%$ of the children with a FASD lived with their parents and $38.4 \%$ elsewhere (e.g. grandparents, foster parents, aunt and uncle). Of the children with a FASD, $4.0 \%$ had a congenital heart defect, $2.0 \%$ seizures, and $4.0 \%$ other conditions (e.g. arthritis, asthma, deafness). Moreover, $6.1 \%$ are currently on medication (e.g. methylphenidate, albuterol). The interviewees also reported that $4.0 \%$ of the children had complaints such as stomach cramps, $4.0 \%$ withheld stools because of inadequate toilet facilities at school, and $5.1 \%$ had problems with passing urine or stool (e.g. painful, burning sensations).

\section{Incontinence}

Rates of incontinence are described in Table 2, and can be inspected at https://osf.io/g683k/. Based on the ICCS guidelines, overall incontinence was present in $20.2 \%(n=20)$ of children with a FASD (FAS $n=17, \operatorname{pFAS} n=1, \operatorname{ARND} n=2)$. No incontinence was reported for children with $\operatorname{ARBD}(n=0)$. NE was present in $16.2 \%(n=16)$ of children (FAS $n=13$, pFAS $n=1$, and ARND $n=2$ ). DUI was reported for one child (FAS), 
Table 1 Sample characteristics.

\begin{tabular}{|c|c|c|c|c|c|}
\hline Variable & $\begin{array}{l}\text { Total FASD } \\
(n=99)\end{array}$ & $\begin{array}{l}\text { FAS } \\
(n=72)\end{array}$ & $\begin{array}{l}\text { pFAS } \\
(n=15)\end{array}$ & $\begin{array}{l}\text { ARND } \\
(n=11)\end{array}$ & $\operatorname{ARBD}(n=1)$ \\
\hline \multicolumn{6}{|l|}{ Maternal characteristics } \\
\hline Mean age at delivery $(S D)^{a, b}$ & $27.14(6.89)$ & $27.99(7.23)$ & $23.99(5.84)$ & $25.89(5.01)$ & 25.61 \\
\hline \multicolumn{6}{|l|}{ Educational attainment (\%) } \\
\hline Primary school & $14(14.1)$ & $12(16.7)$ & $1(6.7)$ & $1(9.1)$ & - \\
\hline High school & $84(84.8)$ & $60(83.3)$ & $14(93.3)$ & $9(81.8)$ & $1(100.0)$ \\
\hline University & $1(1.0)$ & - & - & $1(9.1)$ & - \\
\hline \multicolumn{6}{|l|}{ Child characteristics } \\
\hline Male (\%) & $57(57.6)$ & $42(73.7)$ & $8(14.0)$ & $7(12.3)$ & $0(0.0)$ \\
\hline Mean age of testing in years (SD) & $8.49(0.71)$ & $8.53(0.77)$ & $8.40(0.51)$ & $8.42(0.59)$ & 7.84 \\
\hline \multirow[t]{2}{*}{ Mean birth weight in $\mathrm{g}(\mathrm{SD})^{\mathrm{b}}$} & 2607.92 & 2450.58 & 2903.33 & 3138.18 & 3200.00 \\
\hline & $(535.92)$ & $(474.24)$ & $(508.21)$ & $(437.65)$ & \\
\hline Premature birth $(\%)^{c}$ & $11(11.1)$ & $7(63.6)$ & $3(27.3)$ & $1(9.1)$ & - \\
\hline Mean weight for age in $\mathrm{kg}(\mathrm{SD})^{\mathrm{d}}$ & $17.78(2.53)$ & $17.56(2.46)$ & $17.17(1.86)$ & $19.48(2.64)$ & 24 \\
\hline Mean height for age in $\mathrm{cm}(\mathrm{SD})^{\mathrm{d}}$ & $111.44(6.5)$ & $111.22(6.6)$ & $110.27(6.16)$ & $113.91(6.11)$ & 118 \\
\hline $\begin{array}{l}\text { Mean head circumference or } \\
\text { OFC in } \mathrm{cm}(\mathrm{SD})^{\mathrm{d}}\end{array}$ & $49.9(1.58)$ & $49.75(1.45)$ & $49.93(1.42)$ & $51.6(1.66)$ & 51.1 \\
\hline Mean BMI for age $(S D)^{d}$ & $14.27(1.27)$ & $14.16(1.3)$ & $14.13(1.16)$ & $14.95(0.74)$ & 17.24 \\
\hline \multicolumn{6}{|l|}{ Living } \\
\hline With parents (\%) & $61(61.6)$ & $46(63.9)$ & $9(60.0)$ & $6(54.5)$ & - \\
\hline Other $(\%)$ & $38(38.4)$ & $26(36.1)$ & $6(40.0)$ & $5(45.5)$ & $1(100.0)$ \\
\hline Family members (e.g. grandmother) & $30(30.3)$ & $18(25.0)$ & $6(40.0)$ & $5(45.5)$ & $1(100.0)$ \\
\hline Foster or guardian & $7(7.07)$ & 7 (7.07) & - & - & - \\
\hline Neighbor & $1(1.01)$ & $1(1.01)$ & - & - & - \\
\hline Physical disability or chronic illness (\%) & $10(10.1)$ & $9(12.5)$ & $1(6.67)$ & - & - \\
\hline Congenital heart defect & $4(4.04)$ & $4(5.56)$ & - & - & - \\
\hline Seizures & $2(2.02)$ & $2(2.78)$ & - & - & - \\
\hline Anomalies of the urogenital tract & - & - & - & - & - \\
\hline Other (e.g. asthma, arthritis) & $4(4.04)$ & $3(4.17)$ & $1(6.67)$ & - & - \\
\hline \multicolumn{6}{|l|}{ Griffiths mental development scales (\%) } \\
\hline Mild delay & $6(6.1)$ & $2(0.8)$ & $3(20.0)$ & $1(9.1)$ & $1(100.0)$ \\
\hline Developmental delay & $22(22.2)$ & $12(16.7)$ & $4(26.7)$ & $5(45.5)$ & $0(0.0)$ \\
\hline Severe delay & 71 (71.7) & $58(80.6)$ & $8(53.3)$ & $5(45.5)$ & $0(0.0)$ \\
\hline
\end{tabular}

and FI for four children (all FAS). There were two children who wet their beds less than once a month. No indication of lower urinary tract symptoms (LUTS) in the clinical range was observed as all scores were lower than 13 . Also, no anomalies of the urogenital tract were reported. Questions related to specific symptoms of straining and postponement were not reported, whereas urgency was reported for one child (FAS). Moreover, frequency data showed that $12.1 \%$ of the children

Table 2 Sample point estimates and $95 \% \mathrm{Cl}$ for incontinence among children with FASD.

\begin{tabular}{lllll}
\hline Incontinence & Total FASD & FAS & pFAS & ARND \\
\hline $\begin{array}{l}\text { Overall } \\
\quad \text { incontinence }{ }^{\mathrm{a}}\end{array}$ & $20.2_{n=20}(13-30)$ & $23.6_{n=17}(14.4-35.1)$ & $6.67_{n=1}(0.17-31.95)$ & $18.18_{n=2}(2.28-51.78)$ \\
NE & $16.2_{n=13}(10-25)$ & $18.1_{n=13}(9.98-28.89)$ & $18.06_{n=1}(0.17-31.95)$ & $18.18_{n=2}(2.28-51.78)$ \\
DUI & $1.0_{n=1}(0-6)$ & $1.39_{n=1}(0-7.5)$ & $0_{n=0}(0-21.8)$ & $0_{n=0}(0-28.49)$ \\
FI & $4.0_{n=4}(1-10)$ & $5.56_{n=4}(1.53-13.62)$ & $0_{n=0}(0-21.8)$ & $0_{n=0}(0-28.49)$ \\
\hline
\end{tabular}

This table represents percentages of incontinence sample point estimates including the associated confidence intervals per FASD diagnoses whereby $n$ represents number of cases.

a Overall incontinence was measured when criteria met for: NE "Every night," " $2 \times /$ week or more," or " $2 \times /$ month or more"; DUI, "Every day," " $2 \times /$ week or more," or " $1 \times /$ month or more"; or FI, "Every day," " $2 \times /$ week or more," or " $1 \times /$ month or more." For more details, see https://osf.io/g683k/. 
Table 3 Association between incontinence and Griffiths Mental Development Scales.

\begin{tabular}{|c|c|c|c|c|c|c|c|}
\hline & \multirow[t]{2}{*}{ Group } & \multirow[t]{2}{*}{ Mean } & \multirow[t]{2}{*}{ Std. error } & \multicolumn{2}{|l|}{$95 \% \mathrm{Cl}$} & \multirow[t]{2}{*}{$p$ Value $^{a}$} & \multirow[t]{2}{*}{ Effect size $^{b}$} \\
\hline & & & & Lower & Upper & & \\
\hline \multirow[t]{2}{*}{ Total GQ score } & Incontinence & -2.6 & 0.2 & -3.01 & -2.18 & 0.767 & $0.3(-0.19$ to 0.8$)$ \\
\hline & No incontinence & -2.34 & 0.1 & -2.53 & -2.15 & & \\
\hline \multicolumn{8}{|l|}{ Subscales } \\
\hline \multirow[t]{2}{*}{ A. Locomotor } & Incontinence & -0.41 & 0.24 & -0.92 & 0.1 & 0.8 & $0.25(-0.24$ to 0.74$)$ \\
\hline & No incontinence & -0.13 & 0.13 & -0.38 & 0.12 & & \\
\hline \multirow[t]{2}{*}{ B. Personal-social } & Incontinence & -1.36 & 0.24 & -1.86 & -0.85 & 0.46 & $0.42(-0.07$ to 0.91$)$ \\
\hline & No incontinence & -0.88 & 0.13 & -1.14 & -0.63 & & \\
\hline \multirow[t]{2}{*}{ C. Language } & Incontinence & -2.83 & 0.14 & -3.12 & -2.53 & 0.878 & $-0.11(-0.6$ to 0.38$)$ \\
\hline & No incontinence & -2.88 & 0.04 & -2.96 & -2.79 & & \\
\hline \multirow[t]{2}{*}{ D. Eye-hand coordination } & Incontinence & -2.31 & 0.2 & -2.72 & -1.89 & 0.8 & $0.24(-0.25$ to 0.73$)$ \\
\hline & No incontinence & -2.09 & 0.1 & -2.29 & -1.89 & & \\
\hline \multirow[t]{2}{*}{ E. Performance } & Incontinence & -1.39 & 0.28 & -1.98 & -0.79 & 0.1 & $0.71(0.22$ to 1.21$)$ \\
\hline & No incontinence & -0.38 & 0.16 & -0.7 & -0.06 & & \\
\hline \multirow[t]{2}{*}{ F. Practical reasoning } & Incontinence & -2.62 & 0.27 & -3.17 & -2.06 & 0.906 & $-0.07(-0.56$ to 0.42$)$ \\
\hline & No incontinence & -2.69 & 0.95 & -2.91 & -2.48 & & \\
\hline
\end{tabular}

pass urine one to three times during the day and $87.9 \%$ of the children four to seven times a day.

Subsequent analyses on associations between incontinence and scores on the GMDS-ER scales yielded no significance (Table 3). Children with and without incontinence did not significantly differ in their total GQ scores $(p=0.767)$. Further inspection of scores on the GMDS-ER subscales showed differences in means for example on performance (subscale $\mathrm{E}$ ); respectively mean score of -1.39 for children with incontinence, and mean score of -0.38 without incontinence. These differences yielded no significance after correction for multiple testing $(p=0.1)$. See the supporting information for more details at https://osf.io/g683k/.

\section{Discussion}

This is the first study to analyze and report the prevalence of incontinence in children diagnosed within the spectrum of FASD. The current results provide evidence of overall incontinence to be present in $20 \%$ of children with a FASD in a South African cohort. NE was present in 16\%, DUI was reported for one child, and FI for four children. The most common subtype of reported incontinence was NE. As LUTS were not common, it can be assumed that many children have monosymptomatic NE. The main path mechanisms for the development of NE are polyuria, lack of arousal, and lack of inhibition of the micturition reflex during sleep. All of these are mediated by the CNS, which is also affected in children with a FASD, who have many behavioral and developmental challenges [23,24]. In addition, it is reasonable that environmental factors influenced the current findings. The study took place in a peri-urban area whereby all kind of factors can influence toilet use (e.g. availability or location of toilets). Further research aimed at possible environmental mechanisms responsible for incontinence and its variances is required.
These findings should be interpreted in the light of the limitations of the present study. Notably data on DUI were limited to subjective measures and most probably reflect underreporting of the problem. The low DUI rates could be explained by alternative toilet use (e.g. bushes) and underreporting (e.g. lack of supervision by parents or caregivers). Incontinence was only assessed by interviews and questionnaires without data derived from more objective clinical examination such as bladder diary, uroflowmetry, and ultrasound. Also, a control group of typically developing children was not included. There are no data available regarding incontinence in South African children. Because of the lack of controls in the local population one does not know what the incontinence rates are for day or night in typically developing children, therefore $16 \%$ NE at this age group may be possible. The same holds true for interpreting the low rates of DUI and FI. This indicates the relevance for future investigation in children diagnosed within the spectrum of FASD and typically developing children in this population. Also, it is well known that the prevalence of NE can vary in different ethnic populations. Moreover, the sample was restricted to age 6-10 years and the sample size can be considered as relatively small.

The study also had a number of strengths. First, standardized questionnaires were used by structured interviews during home visits. Second, international guidelines (ICCS; DSM-5) were used in defining subtypes of incontinence $[6,8]$. Third, all interviewees agreed to participate without any drop-outs or incomplete data.

The present study showed that children with a FASD, especially FAS, pFAS, and ARND, are at risk for incontinence. For typically developing children, the prevalence of $\mathrm{NE}$ is reported to be $9.7 \%$ (age 7 years) and 5.5\% (aged 10 years); for DUI, estimates range from $4.9 \%$ to $11.7 \%$ (age 7 years) and $0.8 \%-12.5 \%$ (age $11-12$ years); for $\mathrm{FI}, 0.6 \%-$ $6.9 \%$ (age $5-7$ years) and $0.7 \%-1.6 \%$ (age $10-12$ years) [10]. 
Compared with these rates, the rates among children with a FASD appear to be high. However, follow-up studies should include children with and without a FASD to replicate the current findings.

Previous studies also report gender differences. It is shown that $\mathrm{NE}$ and $\mathrm{FI}$ are more common in boys than girls, and DUI is more common in girls than boys [10]. In the present study, no gender differences were observed.

Prevalence estimates for children with special needs differ between studies. Problems of incontinence increase with the severity of the disability. For children with ADHD and oppositional defiant disorder (aged 4-8 years, mean age 5.7) overall incontinence was reported to be present in 9.1\%, NE 8.5\%, DUI 1.9\%, and FI 0.8\% [25]. For children with Noonan syndrome (aged 4-12 years, mean age 8.19), the rates for NE were $27.3 \%$, DUI 36.4\%, and FI 11.1\% [26]. For children with autism spectrum disorders (aged 5-16 years, mean age 11.3), overall incontinence affected 40\%, NE 30\%, DUI 25\%, and FI 12.5\% [27]. For children with Prader-Willi syndrome (aged 5-12 years), NE was present in 56\%, DUI $1 \%$, and $\mathrm{FI} 1 \%$ of children [28]. For Rett syndrome (5-47 years, mean age 19.34), these rates for NE were as high as $100 \%$, DUI $100 \%$, and FI $58.8-76.0 \%$ [29]. The rates for children with FASD are lower than the rates for many children with special needs, but much higher than for typically developing children. However, NE is the predominant type of incontinence.

The study shows that children diagnosed within the spectrum of FASD have a higher risk of incontinence, especially NE. This has also clinical implications, as it is known that children with ID or neurodevelopmental disorders have much higher rates of incontinence, but do not always receive adequate assessment and treatment because of other more-pressing medical or behavioral symptoms [11]. Vice versa, ID or disorders that affect executive functions (e.g. ADHD), can impair or delay incontinence treatment [30]. As children diagnosed with a FASD may be challenged with ID and/or characteristics of ADHD treatment of incontinence can be more challenging [31]. However, incontinence can be treated effectively in children with ID, genetic syndromes, or neurodevelopmental disorders if their specific problems and needs are taken into consideration. Therefore, an individually adapted assessment and treatment is recommended [11]. Future research is necessary to examine problems of incontinence in relation to cognitive and behavioral functioning among children with a FASD, as well as identifying possible causes.

\section{Conflict of interest}

None.

\section{Funding sources}

None.

\section{Acknowledgements}

The authors would like to thank the Foundation for Alcohol Related Research (FARR) for their contribution to this study, as well as the parents, guardians, and children without whom this study would not have been possible.

\section{References}

[1] BMA Board of Science. Alcohol and pregnancy: preventing and managing fetal alcohol spectrum disorders. London: British Medical Association; 2016. https://www.bma.org.uk/ collective-voice/policy-and-research/public-and-populationhealth/alcohol/alcohol-and-pregnancy.

[2] Hoyme HE, May PA, Kalberg WO, Kodituwakku P, Gossage JP, Trujillo PM, et al. A practical clinical approach to diagnosis of fetal alcohol spectrum disorders: clarification of the 1996 institute of medicine criteria. Pediatrics 2005;115:39-47. http://dx.doi.org/10.1542/peds.2004-0259.

[3] Roozen S, Peters G-JY, Kok G, Townend D, Nijhuis J, Curfs L. Worldwide prevalence of fetal alcohol spectrum disorders: a systematic literature review including meta-analysis. Alcohol Clin Exp Res 2016;40:18-32. http://dx.doi.org/10.1111/acer.12939.

[4] Frey L, Szalda-Petree A, Traci MA, Seekins T. Prevention of secondary health conditions in adults with developmental disabilities: a review of the literature. Disabil Rehabil 2001; 23:361-9. http://dx.doi.org/10.1080/096380010006674.

[5] Streissguth AP. A long-term perspective of FAS. Alcohol Health Res World 1994;18:74-81.

[6] Austin PF, Bauer SB, Bower W, Chase J, Franco I, Hoebeke P, et al. The standardization of terminology of lower urinary tract function in children and adolescents: update report from the standardization committee of the International Children's Continence Society. Neurourol Urodyn 2014;35:471-81. http: //dx.doi.org/10.1002/nau.22751.

[7] Rasquin A, Di Lorenzo C, Forbes D, Guiraldes E, Hyams JS, Staiano A, et al. Childhood functional gastrointestinal disorders: child/adolescent. Gastroenterology 2006;130:1527-37. http://dx.doi.org/10.1053/j.gastro.2005.08.063.

[8] American Psychiatric Association. Diagnostic and statistical manual of mental disorders (DSM-5). 2013. Washington DC.

[9] von Gontard A, Neveus T. Management of disorders of bladder and bowel control in childhood. London: MacKeith Press; 2006.

[10] Franco I, Austin P, Bauer S, von Gontard A, Homsy Y, editors. Pediatric incontinence - evaluation and clinical management. Chicester, UK: John Wiley \& Sons; 2015.

[11] Von Gontard A. Urinary and faecal incontinence in children with special needs. Nat Rev Urol 2013;10:667-74.

[12] Von Wendt L, Similä S, Niskanen P, Järvelin MR. Development of bowel and bladder control in the mentally retarded. Dev Med Child Neurol 1990;32:515-8.

[13] Von Gontard A, Baeyens D, Van Hoecke E, Warzak WJ, Bachmann C. Psychological and psychiatric issues in urinary and fecal incontinence. J Urol 2011;185:1432-6. http: //dx.doi.org/10.1016/j.juro.2010.11.051.

[14] Von Gontard A. Enuresis. In: Rey JM, editor. IACAPAP textbook of child and adolescent mental health. Geneva: International Association for Child and Adolescent Psychiatry and Allied Professions; 2012.

[15] Von Gontard A. Encopresis. In: Rey JM, editor. IACAPAP textbook of child and adolescent mental health. Geneva: International Association for Child and Adolescent Psychiatry and Allied Professions; 2012.

[16] De Gennaro M, Niero M, Capitanucci ML, von Gontard A, Woodward M, Tubaro A, et al. Validity of the international consultation on incontinence questionnaire-pediatric lower urinary tract symptoms: a screening questionnaire for children. J Urol 2010;184:1662-7. http://dx.doi.org/10.1016/ j.juro.2010.03.075.

[17] Luiz DA, Barnard N, Knoesen N, Kotras S, Horrocks P, McAlinden D, et al. Griffiths Mental Development Scales: 
Extended Revised. Two to eight years. Administration manual. Oxford, UK: Hogrefe; 2006.

[18] Olivier L, Louw J, Lambrecht T, Scorgio F, Viljoen D, Chersich M, et al. Pregnant women in the Nelson Mandela Bay Municipality in South Africa used alcohol intentionally to harm their children: fact or fiction?. 2016. Manuscript in preparation.

[19] Stats SA. Statistics South Africa 2011. http://www.statssa. gov.za [Accessed 28 June 2016].

[20] Harris PA, Taylor R, Thielke R, Payne J, Gonzalez N, Conde JG. Research electronic data capture (REDCap) - a metadatadriven methodology and workflow process for providing translational research informatics support. J Biomed Inf 2009; 42:377-81.

[21] Benjamini Y, Hochberg Y. Controlling the false discovery rate: a practical and powerful approach to multiple testing. J R Stat Soc 1995;57:289-300.

[22] Rollins JD, Collins JS, Holden KR. United States head circumference growth reference charts: birth to 21 years. J Pediatr 2010;156. http://dx.doi.org/10.1016/j.jpeds.2010.01.009. 907-913.e2.

[23] Popova S, Lange S, Shield K, Mihic A, Chudley AE, Mukherjee RAS, et al. Comorbidity of fetal alcohol spectrum disorder: a systematic review and meta-analysis. Lancet (London, England) 2016;387:978-87. http://dx.doi.org/10.1016/S0140-6736(15) 01345-8.

[24] Tsang TW, Lucas BR, Carmichael Olson H, Pinto RZ, Elliott EJ. Prenatal alcohol exposure, FASD, and child behavior: a metaanalysis. Pediatrics 2016;137:e20152542. http://dx.doi.org/10. 1542/peds.2015-2542.
[25] Niemczyk J, Equit $M$, Braun-Bither $K$, Klein A-M, von Gontard A. Prevalence of incontinence, attention deficit/hyperactivity disorder and oppositional defiant disorder in preschool children. Eur Child Adolesc Psychiatry 2015;24: 837-43. http://dx.doi.org/10.1007/s00787-014-0628-6.

[26] Niemczyk J, Equit M, Borggrefe-Moussavian S, Curfs L, Von Gontard A. Incontinence in persons with Noonan syndrome. J Pediatr Urol 2015;11. http://dx.doi.org/10.1016/j.jpurol.2015.06.002. 201.e1-201.e5.

[27] Von Gontard A, Pirrung M, Niemczyk J, Equit M. Incontinence in children with autism spectrum disorder. J Pediatr Urol 2015;11. http://dx.doi.org/10.1016/j.jpurol.2015.04.015. 264.e1-7.

[28] Von Gontard A, Didden R, Sinnema M, Curfs L. Urinary incontinence in persons with Prader-Willi syndrome. BJU Int 2010;106:1758-62. http://dx.doi.org/10.1111/j.1464-410X. 2010.09457.x.

[29] Giesbers S, Didden R, Radstaake M, Korzilius H, von Gontard A, Lang $\mathrm{R}$, et al. Incontinence in individuals with Rett syndrome: a comparative study. J Dev Phys Disabil 2012;24:287-300. http://dx.doi.org/10.1007/s10882-012-9271-7.

[30] Crimmins CR, Rathbun SR, Husmann DA. Management of urinary incontinence and nocturnal enuresis in attention-deficit hyperactivity disorder. J Urol 2003;170:1347-50. http: //dx.doi.org/10.1097/01.ju.0000084669.59166.16.

[31] Khoury JE, Milligan K. Comparing executive functioning in children and adolescents with fetal alcohol spectrum disorders and ADHD: a meta-analysis. J Atten Disord 2016:2016. http://dx.doi.org/10.1177/1087054715622016. 